\title{
Editorial: Worries, Threats WAC and a Catastrophe
}

John Carman, Ironbridge International Institute for Cultural Heritage, University of Birmingham, ERI Building, Pritchatts Road, Edgbaston, Birmingham, B15 2TT, UK

E-mail: j.carman@bham.ac.uk

Jan Turek, Center for Theoretical Study, Joint Research Institute of Charles University and the Czech Academy of Sciences, Husova 4, 110 00, Prague 1, Czech Republic

\section{Should We Be Worried?}

On 9th October 2018 in Frankfurt, Germany, the European Union High Representative for Foreign Affairs Federica Mogherini called the European Union a 'world cultural superpower' in her keynote speech at the opening of the 2018 Frankfurt Book Fair. She said:

Culture is an integral part of our European foreign policy. We are by definition, as Europeans, a soft power. And even now that we are investing more than ever in developing our hard power-that sometimes is needed-our European Defence, our strategic autonomy that sometimes might be needed we continue to be a cultural superpower. Let me say, the cultural superpower in the world.

Also stressing the importance of cultural diplomacy, she added that the EU's goal was not to replace national cultural diplomacy, but

on the contrary, we are trying to give it even more strength, joining forces at the European level. For instance, we are starting to build 'Houses of European culture' around the world, as a home for all European cultural institutes and a way to give voice and visibility to all European national cultures abroad.

This journal and its sponsoring organisation, the World Archaeological Congress, are committed to diversity, multivocality, social justice and contesting local and global power geometries within the discipline of archaeology. We are also concerned for the legacies of colonialism and nationalism within the discipline and the rights and ethics relating to cultural property, issues of acquisition, custodianship, conservation, and display. Given our specific interests in these topics, this overt statement of European 'cultural superpower' status and the plans to disseminate evidences of that power across the globe may be a very worrying development. 
The EU was established to ensure not just that European nations would no longer go to war against each other-such wars rapidly turning global-but also to establish a model whereby principles of equality between peoples could be adopted. If Europe is now claiming 'cultural superpower' status, it is going against its own founding principles. The danger is that so much good that has been done since the end of World War 2 may now be undone.

\section{World Heritage on Fire}

On Sunday night 2nd September, Brazil's oldest and most important historical and scientific museum in Rio de Janeiro was consumed by a catastrophic fire, and most (perhaps 90\%) of its 20 million items have been destroyed.

Governments were to blame for failing to support the museum and letting it fall into disrepair. At its 200th anniversary in June, not a single state minister attended the celebration ceremony. Part of the shocking Brazilian government and local authority policy of neglect is the fact that the museum building was not even insured.

Some exhibits survived in a separate annex of the building, including a library of 500,000 books and including works of art dating back to the era of the Portuguese empire.

Among the objects that hopefully may have survived are fragments of the skeletal remains of 'Luzia', an Upper Palaeolithic Paleo-Indian woman who was found in a grotto in Lapa Vermelha, Pedro Leopoldo, Great Belo Horizonte, Brazil, in 1974. It was believed that the young woman may have been part of the first wave of immigrants to South America, 11,500 years ago.

The museum was also home to 700 ancient Egyptian artefacts, including the coffin of Sha-Amun-em-su, an unopened wooden painted coffin from Thebes, dated to around 750 BC. X-ray examination of the coffin suggested that as well as the body, there were amulets still intact inside and these possibly survived the fire. Another earlier coffin that belonged to the priest Hori probably also vanished. Unfortunately, the rest of museum's Egyptology collection was completely destroyed.

The destroyed collection included a total of about 1800 artefacts from the pre-Colombian era, including pieces from Andean cultures such as the Inca, Chancay and Nazca civilisations.

Such a tremendous loss of World heritage is not only a global loss but also a big global issue. Many politicians worldwide are interested in maintaining their own interests, wealth and power. Many politicians who were elected to represent their people have no vision and no respect to their 
people's history. Without changing such attitudes, we may expect even more fire and damage of our heritage and lives.

On 9th October, WAC President Koji Mizoguchi on behalf of the WAC Council issued a statement on the fire in Rio de Janeiro museum that is attached to this editorial.

\section{Dangers on the Danube?}

Universities and academies in Europe and the USA are urging the Hungarian government to withdraw proposed legislation that would effectively ban courses in gender studies in both private and public institutions.

The Hungarian government says that it no longer wishes to accredit and finance such study programmes due to the low number of graduates and a poor track record of employability. These are obviously false, purposeful and politically motivated assessments.

We believe that the Hungarian government should keep universities independent from political, religious and ideological interests, and allow researchers to make their own decision.

The Central European University (CEU) and Eötvös Loránd University in Budapest (ELTE), the only institutions in Hungary that offer degrees in gender studies accredited by the government, were not consulted in advance and had less than $24 \mathrm{~h}$ to react to the decision taken without them.

The ban is undoubtedly part of a series of recent attacks on academic independence and a wider campaign against opposition to the government's socially conservative policies. The current Hungarian government is escalating their efforts to close or evict the Central European University founded in 1991 by philanthropist George Soros on the principles of an open society. CEU decided to continue recruiting students for its Budapest campus, but a new site in Vienna will open for students in the 2019 academic year.

Now one recent personal experience (JT). Three Hungarian scholars coming this summer to Prague for a conference had to refuse the university hotel accommodation as their state-run academic institution can only reimburse accommodation in hotels that are on a government-approved list. This is alarming! Should we worry?

\section{This Issue}

The seven contributions in this issue address issues in four of the world's continents, and especially emphasising the links between different regions 
for good and ill. Two come from opposite ends of Asia, one from Australia, one from Europe and three from Africa. While as so often in our pages, papers involve issues of community engagement-especially with subaltern groups-and heritage management, other disciplinary issues are also addressed. We are especially pleased to see papers addressing issues of archaeological interpretation although as always papers concerning the politics of the field-which find their way into interpretation as well-are directly relevant to us. It is the breadth of coverage that this journal offers that we believe makes it distinctive and valuable.

Àngel Esparza-Arroyo and her colleagues raise a methodological issue about the interpretation of the deposit of adult human remains in childrens' graves in prehistoric Iberia. Frequently characterised as contamination this paper suggests instead deliberate deposition in an era of emerging social complexity, whereby the deposit of older remains relates to changing notions of kinship, to providing protection for deceased infants, to gender construction and to identifying new categories of personhood. The authors offer this as a question that may be of relevance to other parts of the globe.

Continuing the theme of mortuary archaeology, Monika Baumanova examines Swahili pillar tombs in East Africa as a means of creating and maintaining a sense of community cohesion in an area where a strong sense of communal identity did not emerge during the early periods of contact with Europeans. Taking a comparative approach that looks at the Indian Ocean as a region, the paper emphasises intercultural contact.

Shaun Adams and his colleagues are also concerned with examining human remains, but in this case those who were subject to collection as scientific specimens during the period of European colonising of other peoples in the 19th century, were subsequently repatriated for reburial but then faced further exposure by natural erosion. Here, collaboration with the relevant Indigenous community allowed study of the remains giving insight into the treatment of Indigenous peoples by colonisers and thereby contributing to reconciliation via a 'truth-telling' process. The paper thereby emphasises the active role of archaeology in attempting to heal old wounds.

Peter Schmidt and Innocent Pikirayi take us to Africa and a consideration of the ethnocentrism that drives so much archaeology of the historical period-'historic' being defined in Euro-American terms as the era of Western capitalism which ignores and excludes the indigenous African experience grounded in its own deep past and of which literacy may not form a part. This implicit—and institutionalised-racism serves to separate the experience of Western colonisers from those they colonised and give more value to one than the other. The paper offers an approach to breaking the chains that bind the discipline of historical archaeology in North America. 
Beatriz Marín-Aguilera maintains the focus on Africa with a discussion of heritage management initiatives in Morocco which serve to replicate and maintain former colonial power. Emphasising that Western aid is predominately given to former colonies, she argues that the depoliticisation that is so much a part of heritage management practice and the touristic development that goers along with it serves to mask and perpetuate power imbalances which also serve to deny histories of contestation and dissonance.

Qiaowei Wei takes us to China and a consideration of the World Heritage listing process as it has been applied in relation to the Beijing-Hangzhou Grand Canal. Starting from a recognition that exclusive government claims to control of heritage management deny the communitarian values recognised by UNESCO, the paper discusses the integration of social and community values into the process to inform governmental and state-led management practice.

The final-but by no means least-paper remains in Asia but at the opposite end from China.: Samaneh Farokhi and his colleagues consider the rise of subsistence digging at heritage sites in Iran-too often dismissed as 'looting' without deeper consideration-as a response to economic difficulties and downright poverty. The paper offers alternatives to such practices by encouraging educational and job creation initiatives in order to help the people of Iran while safeguarding the valuable archaeological heritage of the country. 


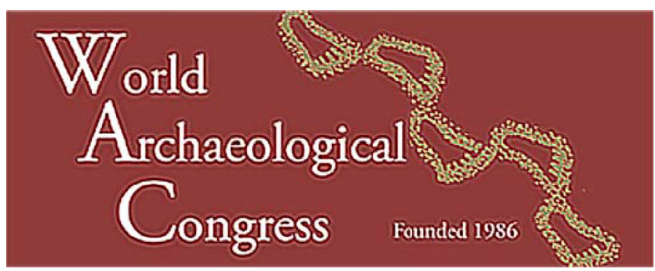

The World Archaeological Congress

9 October, 2018

\section{WAC statement on the devastating fire and loss of heritage housed in the Brazilian National Museum}

On behalf of the entire membership, the WAC Council wants to express our solidarity with the Brazilian people and their National Museum, who suffer from the recent devastating fire and the loss of their heritage as a result.

We are all still in shock, and we share your grief; although the investigation and the search of what can be retrieved are still under way, it seems many of the material testaments and embodiments of human lives, memories and identities housed there have been lost forever. It is not only a tragedy for the Brazilian people and indigenous peoples living in its sovereign territory but also a tragedy for entire humanity.

We also share the anger and grief expressed, particularly concerning the way the Museum had been treated over many years up to the incident. We fully understand the economic difficulty and challenges the Brazilian government and the concerned authorities have been and are faced with and had to tackle. However, without their will and determination to fulfill their duties, the irreplaceable heritage of the Brazilian people, indigenous peoples living in its sovereign territory, and indeed of entire humanity is vulnerable, and this has been proven in the most tragic way.

We believe the loss and destruction of heritage constitute an infringement of basic human rights, the protection and promotion of which the governments and political authorities of the world are obliged to strive for. Once again, we express our solidarity with the museum staff and workers, the Brazilian people and indigenous peoples living in the sovereign territory of Brazil, for their loss, and appeal to the Brazilian government and the concerned authorities to fulfill their duties and to do 
their utmost to prevent a tragedy such as this from happening again by using their powers and the authority mandated to them by the peoples of Brazil.

Koji Mizoguchi

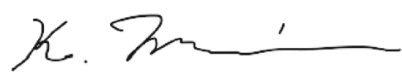

President of the World Archaeological Congress, on behalf of the WAC Council representing the membership

CONTACT PERSON: Professor Koji Mizoguchi (WAC President) Kyushu University Faculty of Social and Cultural Studies 744 Moto'oka, Nishi Ward Fukuoka 819-0395, JAPAN Email: mizog@scs.kyushu-u.ac.jp

\section{Background information}

The World Archaeological Congress, with members in more than 90 countries, is the only fully international and representative organisation of practicing archaeologists. WAC's mission is to (1) promote professional training for disadvantaged nations and communities; (2) broaden public education, involving national and international communities in archaeological research; (3) develop archaeological practice so that it empowers Indigenous and minority groups; (4) contribute to the conservation of archaeological sites threatened by looting, urban growth, tourism, development or war; and (5) re-dress global inequities amongst archaeologists. 